\title{
Adubação fosfatada no cultivo de hortaliças produtoras de raízes
}

\author{
Mariana Vieira Nascimento ${ }^{1}$, Luiz Roberto Silva Guimarães Fernandes ${ }^{1}$, Ricardo Caldas \\ Xavier $^{1}$, Katiane Santiago Silva Benett ${ }^{1}$, Luciana Maria da Silva ${ }^{1}$ \\ ${ }^{1}$ Universidade Estadual de Goiás, Campus de Ipameri, Ipameri, Goiás, Brasil. E-mail: nascimento_mariana1@ hotmail.com, \\ luizrobertofagro@hotmail.com, ricardouna@hotmail.com, katiane.benett@gmail.com, luy.mari@hotmail.com
}

Recebido: 01/11/2017; Aceito: 01/11/2017.

\section{RESUMO}

Objetivou-se avaliar os efeitos de fontes e doses de fertilizantes fosfatados sobre o desenvolvimento e a produtividade de hortaliças produtoras de raízes tuberosas. Foram realizados três experimentos distintos, na Universidade Estadual de Goiás - UEG, Câmpus Ipameri-GO, sendo estudado apenas uma espécie em cada um deles. O delineamento utilizado, para cada experimento, foi o de blocos ao acaso, em esquema fatorial 2 × 5 , sendo utilizado cinco doses de fósforo (P) e duas fontes de $\mathrm{P}$ com quatro repetições. As espécies estudadas foram: cenoura, beterraba e rabanete, as fontes de $\mathrm{P}$ utilizadas foram o Superfosfato simples e o Superfosfato triplo. Foram avaliados a altura de planta; diâmetro e comprimento de raiz; número de folhas; teor de P foliar e de raízes; massa fresca e seca de parte aérea; massa fresca e seca de raiz; produtividade comercial, não comercial e total. A aplicação de fontes e doses de fósforo não influenciaram nos atributos morfológicos e na produtividade da cultura da cenoura e rabanete. Para a cultura da beterraba as fontes de fósforo não influenciaram em nenhuma variável e as doses de fósforo incrementou os atributos morfológicos e produtividade.

Palavras-chave: Cenoura, beterraba, rabanete, hortaliças tuberosas

\section{Phosphate fertilization in crop production of root producing agricultures}

\begin{abstract}
The objective of this study was to evaluate the effects of sources and doses of phosphate fertilizers on the development and productivity of tuberous root vegetables. Three distinct experiments were carried out at the State University of Goiás - UEG, Câmpus Ipameri-GO, and only one species was studied in each one. For each experiment, the experimental design was a randomized block design, in a 2 x 5 factorial scheme, using five doses of phosphorus $(\mathrm{P})$ and two sources of $\mathrm{P}$ with four replicates. The studied species were: carrot, beet and radish, the sources of $\mathrm{P}$ used were single superphosphate and triple superphosphate. Plant height was evaluated; root diameter and length; number of leaves; foliar and root $\mathrm{P}$ content; fresh and dry mass of aerial part; fresh and dry root mass; commercial, non-commercial and total productivity. The application of sources and doses of phosphorus did not influence the morphological attributes and productivity of carrot and radish. For the beet crop the phosphorus sources did not influence any variables and the phosphorus doses increased the morphological attributes and productivity.
\end{abstract}

Key words: Carrot, beet, radish, tuberous vegetables. 


\section{Introdução}

As hortaliças têm apresentado cada vez mais importância na alimentação pois são fontes fundamentais de vitaminas, minerais e fibras, necessárias na dieta humana. São classificadas em três grandes grupos segundo suas partes utilizáveis e comercializáveis: hortaliças-fruto, hortaliças herbáceas e hortaliças tuberosas. Dentre o grupo das hortaliças, as tuberosas apresentam destaque na dieta, cujas partes utilizáveis desenvolvem-se dentro do solo, sendo ricas em carboidratos (FILGUEIRA, 2012).

Para a produção de hortaliças deve-se observar que a exemplo de outros cultivos agrícolas as plantas dependem de fatores relacionados às condições edafoclimáticas para que possam obter um bom desenvolvimento. Dentre estes fatores está a disponibilidade de nutrientes presentes na solução do solo (KOETZ et al., 2012).

É notada uma crescente demanda por fertilizantes nas áreas produtoras de hortaliças visto que estes insumos são utilizados para repor a fertilidade perdida devido ao uso intensivo do solo e, suprir as necessidades nutricionais da planta, conforme a família botânica das mesmas.

Dentre os nutrientes mais exigidos na produção agrícola destaca-se o fósforo $(\mathrm{P})$, nutriente considerado um dos mais limitantes na produção agrícola (HAVLIN et al., 2005). Apesar dos solos agrícolas conterem grandes quantidades de fósforo total, a sua disponibilidade para as plantas é muito pequena devido à sua tendência em formar compostos de baixa solubilidade, dificultando assim sua absorção pelas plantas (BISSANI et al., 2008). Desta forma há necessidade de se fazer uma complementação nutricional através da adubação fosfatada.

Segundo Filgueira (2012) o fósforo favorece o desenvolvimento do sistema radicular das hortaliças aumentando a absorção de água e de nutrientes e, consequentemente, aumenta a qualidade e o rendimento dos produtos colhidos. De acordo com Grant et al. (2001) o suprimento adequado de P é importante já nas fases iniciais de crescimento das plantas pois as limitações na disponibilidade de $\mathrm{P}$ no início do ciclo vegetativo podem resultar em restrições do desenvolvimento da planta sem possibilidades de recuperação ainda que, posteriormente, se aumente o suprimento de $\mathrm{P}$ em níveis adequados.

Nas adubações, o fósforo é geralmente fornecido às plantas na forma de fertilizantes fosfatados solúveis na ocasião do plantio. Dentre as opções de fontes de fósforo disponíveis no mercado, os fosfatos solúveis são os usualmente comercializados, entre eles os grupos dos superfosfatos simples e triplos (HARGER et al., 2007).

O superfosfato simples é obtido pelo tratamento do fosfato de rocha (apatita) com ácido sulfúrico, originando fosfato monocálcio, sulfato de cálcio (gesso) e ácido fluorídrico (RAIJ, 1991). O superfosfato triplo é obtido a partir da rocha fosfatada, consumindo quantidades maiores de ácido sulfúrico que as necessárias para a produção do superfosfato simples, obtendo-se inicialmente gesso e ácido fosfórico, este, por sua vez, reagirá com o material apatítico produzindo o superfosfato triplo (RAIJ, 1991)

$\mathrm{Na}$ literatura são encontrados poucos estudos sobre o efeito de doses e, principalmente, de fontes de fósforo no desenvolvimento e produtividade de hortaliças. Dentre estes, Alves et al. (2008) trabalhando com omissão de fósforo em solução nutritiva no cultivo de beterraba, verificaram arroxeamento intenso das folhas e raízes, menor crescimento da planta e paralisação do crescimento da raiz tuberosa. Avalhaes et al. (2009) observaram que a aplicação de fósforo promoveu incremento no crescimento, no teor foliar de $\mathrm{P}$ e na massa fresca da raiz tuberosa da beterraba.

De forma geral, nota-se na literatura, bem como em pesquisas, que os estudos sobre os efeitos do fósforo na nutrição e produção de hortaliças são escassos, o que se torna motivo de preocupação para o manejo adequado da adubação de olerícolas, uma vez que este macronutriente é limitante à produção destas. Assim para poder refinar as recomendações de adubação existentes para cada espécie de hortaliça são necessários estudos envolvendo o oferecimento do fósforo através de um programa de adubação.

Diante do exposto, desenvolveu-se o presente estudo com o intuito de investigar os efeitos que fontes e doses de fertilizantes fosfatados exercem sobre o desenvolvimento e produtividade de hortaliças produtoras de raízes tuberosas.

\section{Material e Métodos}

Foram desenvolvidos três trabalhos de forma distinta, na área experimental da Universidade Estadual de Goiás - UEG, Câmpus Ipameri, localizada no município de Ipameri-GO com $17^{\circ} 43$ '19" latitude S e 48 09'35" longitude W e altitude de $764 \mathrm{~m}$.

O clima da região, segundo a classificação de Köppen-Geiger conforme Cardoso et al. (2014) é definindo como clima tropical (Aw) constando estação seca no inverno. O solo da área experimental foi classificado como Latossolo VermelhoAmarelo distrófico (SANTOS et al., 2013).

Amostras do solo da área experimental foram retiradas para compor uma amostra completa e posteriormente realizar a análise de fertilidade que apresentou a seguinte composição química: $\mathrm{pH}$ $\left(\mathrm{CaCl}_{2}\right)=5,4 ; \mathrm{H}+\mathrm{Al}=29 \mathrm{mmol}_{\mathrm{c}} \mathrm{dm}^{-3} ; \mathrm{Ca}=19 \mathrm{mmol}_{\mathrm{c}}$ $\mathrm{dm}^{-3} ; \mathrm{Mg}=13 \mathrm{mmol}_{\mathrm{c}} \mathrm{dm}^{-3} ; \mathrm{P}$ (resina) $=20 \mathrm{mg} \mathrm{dm}^{-3} ; \mathrm{K}=$ $3,2 \mathrm{mmol}_{\mathrm{c}} \mathrm{dm}^{-3}$; Matéria orgânica $=26 \mathrm{~g} \mathrm{dm}^{-3}$; CTC $=$ 
64,2 mmol $_{\mathrm{c}} \mathrm{dm}^{-3} ; \mathrm{V} \%=55 ; \mathrm{Cu}=1,0 \mathrm{mg} \mathrm{dm}^{-3}, \mathrm{Fe}=57$ $\mathrm{mg} \mathrm{dm}^{-3}, \mathrm{Mn}=2,9 \mathrm{mg} \mathrm{dm}^{-3}, \mathrm{Zn}=0,3 \mathrm{mg} \mathrm{dm}^{-3},=\mathrm{e} \mathrm{B}=$ $0,15 \mathrm{mg} \mathrm{dm}^{-3}$. O teor de $\mathrm{P}$ apresentado na análise do solo é considerado baixo para hortaliças, conforme Raij et al. (1996).

Foi avaliado o efeito da adubação fosfatada no desenvolvimento das hortaliças tuberosas: cenoura (Daucus carota L.), beterraba (Beta vulgaris L.) e rabanete (Raphanus sativus L.). Não houve adubação de plantio para nenhum dos experimentos. $\mathrm{O}$ delineamento experimental utilizado para cada experimento, foi o de blocos ao acaso, em esquema fatorial $2 \times 5$, sendo utilizadas cinco doses de fósforo (P): 0, 160, 320, 480 e $640 \mathrm{~kg} \mathrm{ha}^{-1}$ de $\mathrm{P}_{2} \mathrm{O}_{5}$, para as culturas da cenoura e da beterraba e $0,70,140,210$ e $280 \mathrm{~kg} \mathrm{ha}^{-1}$ de $\mathrm{P}_{2} \mathrm{O}_{5}$ para a cultura do rabanete e duas fontes de $\mathrm{P}$ (Superfosfato simples e Superfosfato triplo com $18 \%$ e $46 \%$ de $\mathrm{P}_{2} \mathrm{O}_{5}$, respectivamente) com quatro repetições. Os tratamentos foram aplicados no plantio em todas as espécies estudadas.

Para cada experimento foram preparados quatro canteiros com 1,0 $\mathrm{m}$ de largura, 0,25 $\mathrm{m}$ de altura e comprimento variável em função dos espaçamentos utilizados para cada espécie. A semeadura foi realizada diretamente nos canteiros com espaçamento de $0,25 \mathrm{x}$ $0,05 \mathrm{~m} ; 0,20 \times 0,10 \mathrm{~m} \mathrm{e} 0,20 \times 0,10 \mathrm{~m}$, para as culturas da cenoura, beterraba e rabanete respectivamente.

As parcelas experimentais foram constituídas de quatro linhas espaçadas de acordo com o espaçamento da espécie utilizada e comprimento de 1,0 m. A área útil constou das duas linhas centrais de cada parcela.

Com o intuito de evitar a competição por água e nutrientes foi realizado o controle das plantas invasoras, através de capinas manuais, sempre que necessário e o controle de pragas aplicando-se inseticidas recomendados para cada cultura. O fornecimento de água foi realizado por meio de sistema de irrigação por aspersão convencional duas vezes ao dia ou sempre que necessário. As colheitas foram iniciadas aos 30, 60 e 80 dias após o plantio para as culturas do rabanete, beterraba e cenoura, respectivamente, de forma manualmente puxando-se a parte aérea com o solo úmido. As raízes colhidas foram destacadas das folhas, lavadas e analisadas.

Verificou-se o efeito dos tratamentos sobre o desenvolvimento das plantas, avaliando-se para todas as culturas a altura média das plantas, medindo-se a distância entre a superfície do solo até a parte mais alta da planta; número de folhas, onde foram contadas as folhas que compõem a planta; diâmetro médio de raízes através da circunferência das raízes, com a utilização de um paquímetro; comprimento de raízes, medindo-se com uma régua graduada a distância entre as extremidades da raiz.
Para a determinação da massa fresca da parte aérea e raiz, as folhas e as raízes foram pesadas separadamente. Para a mensuração da massa seca de parte aérea e raíz estas foram acondicionadas em sacos de papel do tipo $\mathrm{Kraft}^{\circledR}$ e secas em estufa a $65^{\circ} \mathrm{C}$ até atingirem peso constante, posteriormente foram pesadas em balança analítica com precisão de $0,01 \mathrm{~g}$. Após a determinação da massa seca de parte aérea e raízes o material foi moído em moinho tipo Willey equipado com peneira de malhas com abertura de $1,0 \mathrm{~mm}$ para posterior determinação dos teores de $\mathrm{P}$ foliar e de raízes.

A produtividade comercial $\left(\mathrm{t} \mathrm{ha}^{-1}\right)$ foi obtida com o somatório das produções de raízes sem defeitos (raízes bifurcadas, deformadas e com ramificações excessivas, com presença de galhas); a produtividade não comercial $\left(\mathrm{t} \mathrm{ha}{ }^{-1}\right)$ revelou a produção de raízes com defeitos; a produtividade total obteve-se com a somatória da produtividade comercial e não comercial.

Os dados foram submetidos à análise de variância (teste F) e as médias comparadas pelo teste Tukey a 5\% de probabilidade. Quando significativo para as doses de fósforo foram ajustadas análises de regressão. As análises estatísticas foram processadas através do programa de análise estatística Sanest.

\section{Resultados e Discussão}

Não foram observados efeito da interação entre as fontes e doses de fósforo para nenhuma das variáveis avaliadas nos experimentos com as culturas da cenoura e rabanete (Tabelas 1, 2, 5 e 6 ).

\section{Cultura da Cenoura}

Os valores médios de altura de planta, diâmetro de raiz, comprimento de raiz, número de folhas, teor de $\mathrm{P}$ foliar, e teor de $\mathrm{P}$ na raiz estão disponíveis na Tabela 1 . A adubação fosfatada não influenciou de forma significativa nas variáveis apresentadas na Tabela 1 . Observa-se que os valores para a altura de plantas, diâmetro e comprimento de raiz encontrados neste trabalho são próximos aos encontrados por Silva et al. (2017) trabalhando com diferentes fertilizantes na cultura da cenoura. $\mathrm{O}$ efeito da aplicação de nutrientes é dependente das condições climáticas, tipo de solo, cultivar dentre outros fatores. Conforme Filgueira (2012), a utilização de doses mais elevadas de 250 a 400 $\mathrm{kg} \mathrm{ha}^{-1}$ de $\mathrm{P}$, pode apresentar efeitos significativos para altura de planta e diâmetro de raiz, fato este não observado neste trabalho.

Os valores de $\mathrm{P}$ foliar estão acima $2,2 \mathrm{~g} \mathrm{~kg}^{-1}$, valor este sugerido por Ribeiro et al. (1999), desta forma pode se afirmar que mesmo não ocorrendo diferenças significativas entre os tratamentos, a cultura se desenvolveu de forma satisfatória. Na Tabela 2 são apresentados os resultados das avaliações. 
Tabela 1. Altura de planta (ALT), diâmetro de raiz (DR), comprimento de raiz (CR), número de folhas (NF), teor de P foliar e teor de P na raiz de cenoura em função de doses e fontes de fósforo. Ipameri-GO, 2015.

\begin{tabular}{|c|c|c|c|c|c|c|}
\hline \multirow{2}{*}{ Fontes } & ALT & DR & $\mathrm{CR}$ & NF & Teor de $\mathrm{P}$ foliar & Teor de $\mathrm{P}$ raiz \\
\hline & $\mathrm{cm}$ & $\mathrm{mm}$ & $\mathrm{cm}$ & --- & \multicolumn{2}{|c|}{---- $\mathrm{g} \mathrm{kg}^{-1} \mathrm{MS}$---- } \\
\hline Superfosfato Simples & 54,19 a & $21,14 \mathrm{a}$ & $15,20 \mathrm{a}$ & $7,35 \mathrm{a}$ & $2,71 \mathrm{a}$ & $2,28 \mathrm{a}$ \\
\hline Superfosfato Triplo & $53,45 \mathrm{a}$ & $26,83 \mathrm{a}$ & $15,04 \mathrm{a}$ & $7,65 \mathrm{a}$ & $2,89 \mathrm{a}$ & $2,59 \mathrm{a}$ \\
\hline Valor F & $0,256^{\text {ns }}$ & $0,703^{\text {ns }}$ & $0,102^{\text {ns }}$ & $0,001^{\mathrm{ns}}$ & $1,031^{\mathrm{ns}}$ & $1,224^{\mathrm{ns}}$ \\
\hline \multicolumn{7}{|l|}{$\overline{\text { Doses }\left(\mathrm{kg} \mathrm{ha}^{-1}\right)}$} \\
\hline 0 & 51,40 & 19,45 & 15,20 & 7,55 & 2,45 & 2,30 \\
\hline 160 & 53,55 & 22,66 & 16,20 & 7,57 & 2,56 & 2,36 \\
\hline 320 & 56,07 & 21,87 & 14,87 & 7,25 & 2,68 & 2,68 \\
\hline 480 & 55,52 & 22,47 & 14,82 & 7,22 & 2,89 & 2,58 \\
\hline 640 & 52,55 & 20,98 & 14,50 & 7,15 & 2,95 & 2,64 \\
\hline Valor F & $1,454^{\text {ns }}$ & $2,041^{\text {ns }}$ & $1,366^{\mathrm{ns}}$ & $0,309^{\text {ns }}$ & $0,932^{\mathrm{ns}}$ & $1,479^{\text {ns }}$ \\
\hline Regressão & --- & --- & --- & --- & --- & --- \\
\hline Interação & --- & --- & $\begin{array}{ll}-- \\
-\end{array}$ & --- & --- & --- \\
\hline $\mathrm{CV}(\%)$ & 8,58 & 9,10 & 10,44 & 13,66 & 9,76 & 10,12 \\
\hline
\end{tabular}

Médias seguidas de mesma letra maiúscula na coluna, para cada fator estudado, não diferem entre si pelo teste de Tukey a $5 \%$ de probabilidade. ${ }^{\text {ns }}=$ não significativo

Tabela 2. Massa fresca de parte aérea (MFPA) massa seca de parte aérea (MSPA), massa fresca de raiz (MFR) massa seca de raiz (MSR), produtividade comercial (PC), produtividade não comercial (PNC) e produtividade total (PT) de cenoura em função de doses e fontes de fósforo. Ipameri-GO, 2015.

\begin{tabular}{|c|c|c|c|c|c|c|c|}
\hline \multirow[t]{2}{*}{ Fontes } & MFPA & MSPA & MFR & MSR & $\mathrm{PC}$ & $\mathrm{PNC}$ & PT \\
\hline & \multicolumn{4}{|c|}{ 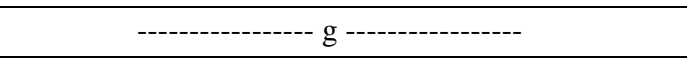 } & \multicolumn{3}{|c|}{------- t ha $^{-1}$------- } \\
\hline Superfosfato Simples & $40,32 \mathrm{a}$ & $7,86 \mathrm{a}$ & 36,96 a & $8,27 \mathrm{a}$ & 37,77 a & $18,62 \mathrm{a}$ & $51,39 \mathrm{a}$ \\
\hline Superfosfato Triplo & $41,32 \mathrm{a}$ & $7,70 \mathrm{a}$ & 36,79 a & 7,96 a & 38,03 a & $18,50 \mathrm{a}$ & $56,04 \mathrm{a}$ \\
\hline Valor F & $0,050^{\mathrm{ns}}$ & $0,130^{\mathrm{ns}}$ & $0,002^{\mathrm{ns}}$ & $1,059^{\mathrm{ns}}$ & $0,003^{\text {ns }}$ & $0,001^{\mathrm{ns}}$ & $0,634^{\mathrm{ns}}$ \\
\hline \multicolumn{8}{|l|}{ Doses $\left(\mathrm{kg} \mathrm{ha}^{-1}\right)$} \\
\hline 0 & 44,40 & 8,27 & 36,90 & 8,52 & 30,43 & 12,33 & 42,76 \\
\hline 160 & 31,50 & 6,86 & 30,32 & 8,05 & 43,01 & 20,31 & 63,33 \\
\hline 320 & 45,28 & 8,08 & 35,51 & 7,82 & 38,57 & 21,16 & 45,98 \\
\hline 480 & 36,32 & 7,52 & 42,43 & 8,05 & 37,43 & 18,69 & 56,13 \\
\hline 640 & 46,60 & 8,16 & 39,20 & 8,12 & 40,05 & 20,32 & 60,38 \\
\hline Valor F & $1,737^{\mathrm{ns}}$ & $1,508^{\mathrm{ns}}$ & $1,446^{\mathrm{ns}}$ & $0,575^{\mathrm{ns}}$ & $0,882^{\text {ns }}$ & $1,468^{\mathrm{ns}}$ & $1,892^{\mathrm{ns}}$ \\
\hline Regressão & --- & --- & --- & --- & --- & --- & --- \\
\hline Interação & --- & --- & --- & --- & --- & --- & --- \\
\hline $\mathrm{CV}(\%)$ & 34,59 & 17,45 & 28,72 & 11,73 & 37,11 & 45,19 & 34,37 \\
\hline
\end{tabular}

Médias seguidas de mesma letra maiúscula na coluna, para cada fator estudado, não diferem entre si pelo teste de Tukey a $5 \%$ de probabilidade. ${ }^{\text {ns }}=$ não significativo.

Naves Filho et al. (2004) ao trabalhar com diferentes doses de fósforo na cultura da cenoura constatou um incremento linear em relação a massa fresca e massa seca da raiz, porém com peso superior, $11,06 \mathrm{~g}$, aos encontrados neste trabalho

Para as doses de $\mathrm{P}$ não foram observadas interações significativas para a massa fresca e seca de parte aérea e raiz, bem como para a produtividade. Estes resultados divergem aos de Araújo et al. (2004) que obtiveram aumento da produtividade em função do aumento das doses de P. Quando o fósforo se encontra em excesso pode causar a deprimência da fixação de $\mathrm{CO}_{2} \mathrm{e}$ a síntese de amido (MARSCHNER, 1995), fato que pode ser uma possível explicação por não se observar diferenças significativas nas variáveis analisadas. Na literatura são apontados vários outros fatores que podem afetar o processo absorção, tais como a temperatura e oxigênio.

\section{Cultura da beterraba}

Não foram detectadas interações significativas entre as fontes e as doses de P utilizadas em nenhuma das características morfológicas estudadas para a cultura da beterraba (Tabela 3).

Os resultados encontrados divergem aos de Avalhaes et al. (2009) trabalhando com rendimento e crescimento de beterraba em função da adubação 
fosfatada observaram diferenças significativas na parte aérea e nas raízes das plantas de beterraba. Oliveira et al. (2016) também observaram resultados divergentes aos encontrados neste trabalho quando avaliaram adubação fosfatada e potássica na beterraba no vale do Itajaí, onde a adubação com fósforo influenciou a massa fresca e seca da raiz além do diâmetro de raiz.

Ressalta-se que apesar de não ocorrer diferenças significativas para os teores de $\mathrm{P}$ foliar (Tabela 3), os valores obtidos são superiores aos valores considerados aceitáveis para a beterraba ( 2 a $4 \mathrm{~g} \mathrm{~kg}^{-1}$ ), segundo Raij et al. (1997).

$\mathrm{O}$ aumento das doses de $\mathrm{P}$ determinou variações significativas somente para o diâmetro e comprimento de raízes de beterraba com ajuste dos dados a regressões lineares. Para o diâmetro houve aumento linear com o incremento das doses de $\mathrm{P}$ (Figura 1A), sendo 18\% superior para a dose de $640 \mathrm{~kg} \mathrm{ha}^{-1}$ de $\mathrm{P}(48,25 \mathrm{~mm}) \mathrm{em}$ relação à dose $0 \mathrm{~kg} \mathrm{ha}^{-1}$ de $\mathrm{P}(40,83 \mathrm{~mm})$. Estes resultados são superiores aos valores máximos encontrados por Oliveira et al. (2016) quando observaram diâmetro de $39,10 \mathrm{~mm}$ para a dose de 375 $\mathrm{kg} \mathrm{ha}^{-1}$ de $\mathrm{P}$; para o comprimento de raízes houve efeito negativo à medida que se aumentaram as doses aplicadas de $\mathrm{P}$, sem interferência das fontes utilizadas, conforme apresentado na Figura 1B.

Pode-se observar que na literatura, a maioria das tabelas de recomendação são de antigas pesquisas que trabalharam com variedades pouco utilizadas atualmente devido ao seu baixo potencial de produção, por isso as variedades atuais, melhoradas, tendem a apresentar resultados divergentes.

Tabela 3. Altura de planta (ALT), diâmetro de raiz (DR), comprimento de raiz (CR), número de folhas (NF), teor de $\mathrm{P}$ foliar e teor de $\mathrm{P}$ nas raízes de beterraba em função de doses e fontes de fósforo. Ipameri-GO, 2015.

\begin{tabular}{|c|c|c|c|c|c|c|}
\hline \multirow{2}{*}{ Fontes } & ALT & DR & $\mathrm{CR}$ & NF & Teor de $\mathrm{P}$ foliar & Teor de $\mathrm{P}$ raiz \\
\hline & $\mathrm{cm}$ & $\mathrm{mm}$ & $\mathrm{cm}$ & --- & \multicolumn{2}{|c|}{------ g kg$^{-1}$ MS ----- } \\
\hline Superfosfato Simples & $41,13 \mathrm{a}$ & $42,88 \mathrm{a}$ & $3,90 \mathrm{a}$ & $5,77 \mathrm{a}$ & $5,65 \mathrm{a}$ & $4,87 \mathrm{a}$ \\
\hline Superfosfato Triplo & $40,76 \mathrm{a}$ & $45,37 \mathrm{a}$ & $3,83 \mathrm{a}$ & $6,04 \mathrm{a}$ & $5,98 \mathrm{a}$ & $4,90 \mathrm{a}$ \\
\hline Valor F & $0,065^{\text {ns }}$ & $3,113^{\text {ns }}$ & $0,045^{\text {ns }}$ & $0,724^{\mathrm{ns}}$ & $1,050^{\mathrm{ns}}$ & $1,304^{\mathrm{ns}}$ \\
\hline \multicolumn{7}{|l|}{ Doses $\left(\mathrm{kg} \mathrm{ha}^{-1}\right)$} \\
\hline 0 & 38,00 & --- & --- & 5,66 & 4,86 & 4,32 \\
\hline 160 & 41,10 & --- & --- & 6,30 & 5,32 & 4,55 \\
\hline 320 & 41,06 & --- & --- & 6,20 & 5,87 & 5,98 \\
\hline 480 & 43,30 & --- & --- & 5,86 & 5,97 & 4,76 \\
\hline 640 & 41,26 & --- & --- & 5,50 & 5,99 & 4,97 \\
\hline Valor F & $1,336^{\mathrm{ns}}$ & $4,141^{*}$ & $5,549 * *$ & $0,947^{\text {ns }}$ & $2,341^{\mathrm{ns}}$ & $1,987^{\text {ns }}$ \\
\hline Regressão & --- & $\mathrm{L}$ & $\mathrm{L}$ & --- & --- & --- \\
\hline Interação & $\begin{array}{ll}-- \\
\end{array}$ & $\begin{array}{ll}-- \\
\end{array}$ & $\begin{array}{ll}-- \\
\end{array}$ & $\begin{array}{ll}-- \\
\end{array}$ & $\begin{array}{ll}-- \\
\end{array}$ & $\begin{array}{ll}-- \\
\end{array}$ \\
\hline $\mathrm{CV}(\%)$ & 9,81 & 8,77 & 22,31 & 14,53 & 13,25 & 12,56 \\
\hline
\end{tabular}

Médias seguidas de mesma letra maiúscula na coluna, para cada fator estudado, não diferem entre si pelo teste de Tukey a $5 \%$ de probabilidade. ${ }^{\text {ns }}=$ não significativo; * significativo a 5\%; ** significativo a $1 \% ; \mathrm{L}=$ regressão linear.
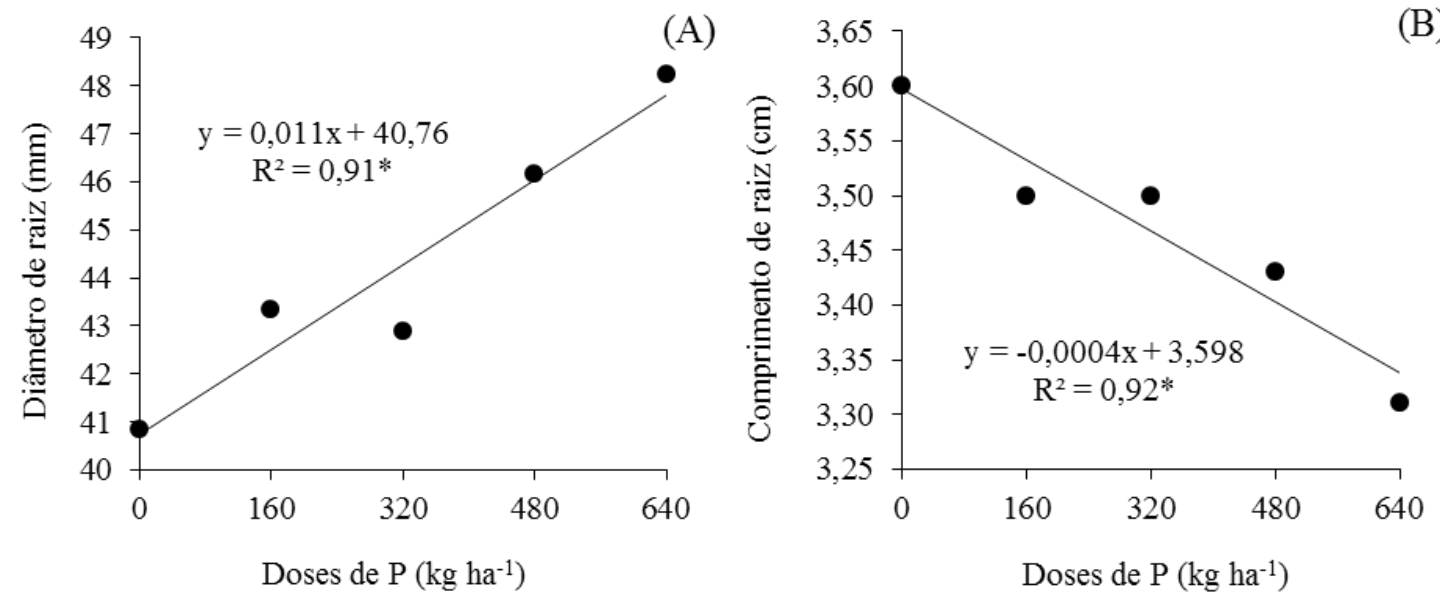

(B)

Figura 1. Valores médios para diâmetro de raiz (A) e comprimento de raiz (B) de beterraba em função da adubação fosfatada. Ipameri-GO, 2015. * significativo a $5 \%$ de probabilidade. 
No que se refere à massa fresca e seca de parte aérea, massa fresca e seca de raiz, produtividade comercial, produtividade não comercial e produtividade total de beterraba, constatou-se que as fontes utilizadas não diferiram entre si para nenhumas das variáveis analisadas (Tabela 4).

As doses de $P$ não influenciaram significativamente na massa fresca e seca da parte aérea e de raízes e na produtividade total da beterraba (Tabela 4). Estes resultados divergem do encontrado por Oliveira et al. (2016) que trabalhando com calibração da adubação fosfatada e potássica para beterraba na região do Vale do Itajaí observou influência da adubação fosfatada para massa fresca e seca da raiz com aplicação de 385 e $470 \mathrm{~kg} \mathrm{ha}^{-1}$ de P, respectivamente.

A produtividade não comercial da beterraba foi influenciada conforme o aumento das doses de $\mathrm{P}$, com ajuste dos dados à regressão linear (Figura 2A). Houve interação significativa entre os fatores fonte $\mathrm{e}$ doses de fósforo para a produtividade comercial da beterraba, conforme ilustrado na Figura 2B. Tanto a aplicação do superfosfato simples como o superfosfato triplo proporcionaram incremento na produtividade comercial da beterraba, cujos dados se ajustaram a regressões lineares positivas para ambos os fertilizantes. O superfosfato triplo apresentou $23 \%$ de incremento na produção comercial de beterraba na dose $640 \mathrm{~kg} \mathrm{ha}^{-1}$ de $\mathrm{P}$ em relação ao superfosfato simples, cuja porcentagem representa $10,3 \mathrm{t} \mathrm{ha}^{-1} \mathrm{de}$ beterraba. De acordo com Luz et al. (2013), o P é importante para o desenvolvimento do tubérculo, maximizando os processos metabólicos das plantas, tais como a translocação de fotoassimilados.
Desta forma, os resultados encontrados neste trabalhão estão de acordo com os obtidos por Avalhaes et al. (2009) que observaram incremento na produção de beterraba em função de doses de $P$.

\section{Cultura do rabanete}

$\mathrm{Na}$ avaliação do efeito da adubação fosfatada sobre o cultivo de rabanete observa-se que altura de planta, diâmetro de raiz, comprimento de raiz, número de folhas e teores de $\mathrm{P}$ foliar e da raiz não apresentaram interações significativas com a aplicação do superfosfato simples e o superfosfato triplo (Tabela 5).

Para o efeito das doses de fósforo observa-se que não houve efeito significativo para os atributos morfológicos e os teores de P. Os resultados de número de folhas, altura de plantas e diâmetro de raiz obtidos neste estudo são divergentes aos de Nunes et al. (2014) que obtiveram ajuste ao modelo quadrático para essas variáveis com teor de $\mathrm{P}$ no solo de $2,4 \mathrm{mg}$ $\mathrm{dm}^{-3}$ (Mehlich-1), atingindo a máxima produção (18 folhas) com a dose de $309,80 \mathrm{mg} \mathrm{dm}^{-3}$ de $\mathrm{P}_{2} \mathrm{O}_{5}$, máxima altura de plantas com a dose de fósforo de $251,32 \mathrm{mg} \mathrm{dm}^{-3}$, que proporcionou plantas com 27,61 $\mathrm{cm}$ e com incremento até a dose de $245 \mathrm{mg} \mathrm{dm}^{-3} \mathrm{de}$ $\mathrm{P}_{2} \mathrm{O}_{5}$, resultando em um incremento de $80 \%$ com diâmetro máximo de 37,69 mm. Oliveira et al. (2010) cultivando rabanete em Latossolo Vermelho Amarelo, verificaram ajuste ao modelo quadrático de regressão para produção de folhas em função das doses de fósforo, porém, encontraram máxima produção com $471,33 \mathrm{mg} \mathrm{dm}^{-3}$ de $\mathrm{P}_{2} \mathrm{O}_{5}$ em solo com teor de 20,2 $\mathrm{mg} \mathrm{dm}^{-3}$ (Mehlich-1).

Tabela 4. Valores médios de massa fresca de parte aérea (MFPA) massa seca de parte aérea (MSPA), massa fresca de raiz (MFR) massa seca de raiz (MSR) e produtividade comercial (PC), produtividade não comercial (PNC) e produtividade total (PT) de beterraba em função da adubação fosfatada. Ipameri-GO, 2015.

\begin{tabular}{|c|c|c|c|c|c|c|c|}
\hline Fontes & MFPA & MSPA & MFR & MSR & $\mathrm{PC}$ & PNC & PT \\
\hline & \multicolumn{4}{|c|}{---------------- g ---------------- } & \multicolumn{3}{|c|}{------- t ha $^{-1}$------- } \\
\hline Superfosfato Simples & $44,52 \mathrm{a}$ & $6,96 \mathrm{a}$ & $69,42 \mathrm{a}$ & $12,60 \mathrm{a}$ & --- & $13,95 \mathrm{a}$ & $54,10 \mathrm{a}$ \\
\hline Superfosfato Triplo & $44,04 \mathrm{a}$ & $6,30 \mathrm{a}$ & $57,00 \mathrm{a}$ & $10,61 \mathrm{a}$ & --- & $11,25 \mathrm{a}$ & $57,02 \mathrm{a}$ \\
\hline Valor de F & $0,012^{\mathrm{ns}}$ & $1,138^{\mathrm{ns}}$ & $4,128^{\mathrm{ns}}$ & $3,322^{\text {ns }}$ & $2,513^{\mathrm{ns}}$ & $1,998^{\mathrm{ns}}$ & $1,030^{\mathrm{ns}}$ \\
\hline \multicolumn{8}{|l|}{ Doses $\left(\mathrm{kg} \mathrm{ha}^{-1}\right)$} \\
\hline 0 & 27,76 & 5,05 & 52,00 & 8,60 & --- & -- & 52,13 \\
\hline 160 & 56,30 & 7,56 & 48,51 & 10,30 & --- & --- & 53,15 \\
\hline 320 & 50,06 & 8,35 & 65,50 & 13,80 & --- & --- & 53,01 \\
\hline 480 & 49,65 & 6,63 & 70,16 & 15,06 & --- & --- & 54,06 \\
\hline 640 & 37,65 & 5,56 & 54,86 & 10,26 & --- & --- & 56,52 \\
\hline Valor F & $2,334^{\mathrm{ns}}$ & $1,98^{\mathrm{ns}}$ & $2,368^{\mathrm{ns}}$ & $1,209^{\mathrm{ns}}$ & $4,747 *$ & $9,255^{*}$ & $2,488^{\mathrm{ns}}$ \\
\hline Regressão & --- & --- & --- & --- & --- & $\mathrm{L}$ & --- \\
\hline Interação & --- & --- & --- & --- & $\mathrm{L} / \mathrm{L}$ & --- & --- \\
\hline$\overline{\mathrm{CV}}(\%)$ & 27,37 & 25,28 & 26,49 & 25,72 & 22,52 & 28,83 & 23,56 \\
\hline
\end{tabular}

Médias seguidas de mesma letra maiúscula na coluna, para cada fator estudado, não diferem entre si pelo teste de Tukey a $5 \%$ de probabilidade. ${ }^{\text {ns }}=$ não significativo; * significativo a $5 \% ; \mathrm{L}=$ regressão linear. 

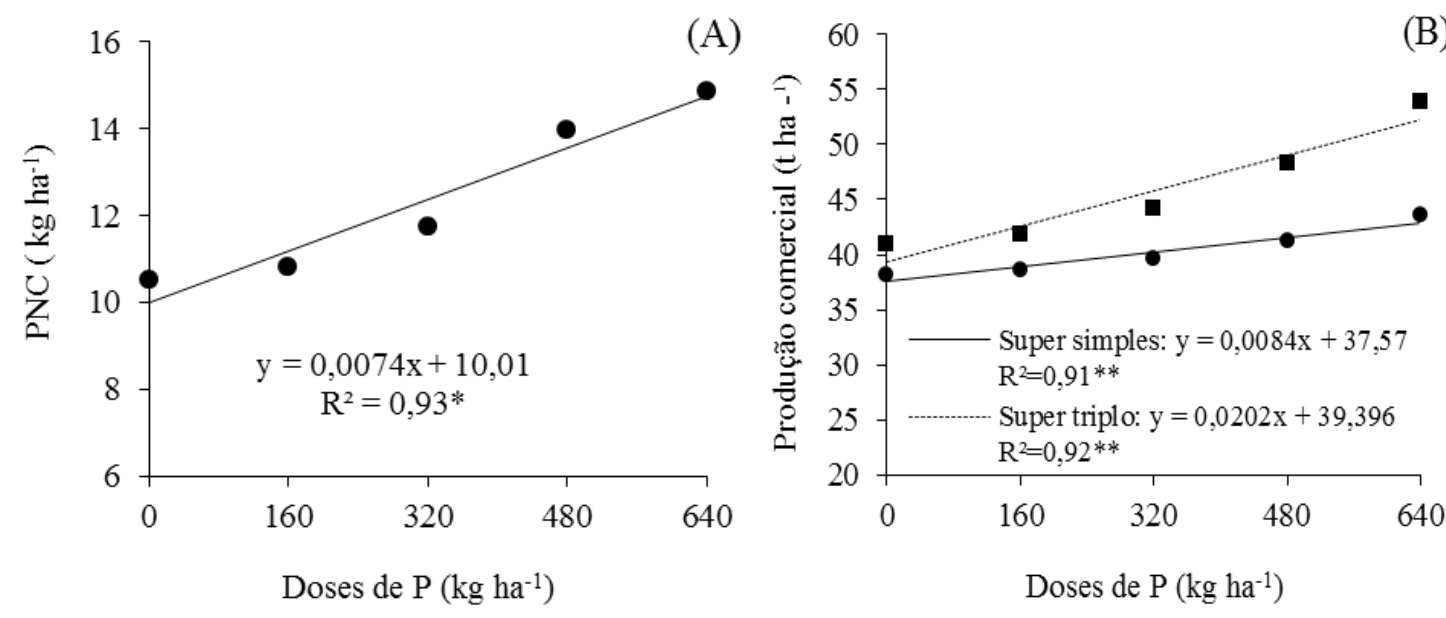

Figura 2. Valores médios para produtividade não comercial (PNC) de raízes de beterraba em função da adubação fosfatada (A) e produtividade comercial (B) da interação entre fontes e doses de fosforo em raízes de beterraba. Ipameri-GO, 2015. *, ** significativo a 5 e $1 \%$ de probabilidade, respectivamente.

$\mathrm{Na}$ avaliação do efeito da adubação fosfatada sobre o cultivo de rabanete observa-se que os valores médios de massa fresca de parte aérea (MFA), massa seca da parte aérea (MSPA), massa fresca de raiz (MFR) massa seca de raiz (MSR), produtividade comercial (PC), produtividade não comercial (PNC) e produtividade total (PT) não apresentaram interações significativas com a aplicação do superfosfato simples e o superfosfato triplo (Tabela 6).

Para massa seca de parte aérea observou-se efeito significativo, sendo que a adubação com superfosfato triplo proporcionou plantas com massa seca superior àquelas adubadas com superfosfato simples (Tabela 6).

Para as doses de fósforo não houve efeito significativo para nenhuma variável analisada neste estudo. Nunes et al. (2014) observaram efeito das doses de $\mathrm{P}_{2} \mathrm{O}_{5}$ para as variáveis massa fresca e seca de raiz, cujos valores se ajustaram à regressão quadrática. Mesmo não ocorrendo efeito significativo para essas variáveis é importante ressaltar que os valores dessas variáveis ficaram próximos ao encontrados na literatura.

A não ocorrência de efeito significativo nas variáveis analisadas na cultura do rabanete pode ser relacionada ao teor de $\mathrm{P}$ no solo. Mesmo apresentando valor baixo, as plantas não apresentaram sintomas de deficiência visual, sendo suficiente para o seu bom desenvolvimento a quantidade aplicada e a disponível no solo. Trabalhos realizados por diversos autores estudando o feito da aplicação de $\mathrm{P}$, observaram influência da aplicação fosfatada em solos com teor de P inferior a $10 \mathrm{mg} \mathrm{dm}^{-1}$.

Tabela 5. Altura de planta (ALT), diâmetro de raiz (DR), comprimento de raiz (CR), número de folhas (NF), teor de $\mathrm{P}$ foliar e teor de $\mathrm{P}$ nas raízes de rabanete em função da adubação fosfatada. Ipameri-GO, 2015.

\begin{tabular}{|c|c|c|c|c|c|c|}
\hline \multirow{2}{*}{ Fontes } & ALT & DR & $\mathrm{CR}$ & $\mathrm{NF}$ & Teor de $\mathrm{P}$ foliar & Teor de $\mathrm{P}$ raiz \\
\hline & $\mathrm{cm}$ & $\mathrm{mm}$ & $\mathrm{cm}$ & --- & \multicolumn{2}{|c|}{----- $\mathrm{g} \mathrm{kg}^{-1} \mathrm{MS}$} \\
\hline Superfosfato Simples & $23,85 \mathrm{a}$ & $35,04 \mathrm{a}$ & $4,42 \mathrm{a}$ & $7,46 \mathrm{a}$ & $5,54 \mathrm{a}$ & $7,15 \mathrm{a}$ \\
\hline Superfosfato Triplo & $22,68 \mathrm{a}$ & $35,98 \mathrm{a}$ & 4,17 a & $7,44 \mathrm{a}$ & $5,62 \mathrm{a}$ & $7,78 \mathrm{a}$ \\
\hline Valor F & $1,565^{\mathrm{ns}}$ & $0,529^{\mathrm{ns}}$ & $1,879^{\mathrm{ns}}$ & $0,005^{\mathrm{ns}}$ & $0,957^{\mathrm{ns}}$ & $1,039^{\mathrm{ns}}$ \\
\hline \multicolumn{7}{|l|}{ Doses $\left(\mathrm{kg} \mathrm{ha}^{-1}\right)$} \\
\hline 0 & 21,57 & 35,45 & 4,17 & 7,27 & 4,56 & 6,99 \\
\hline 70 & 22,42 & 36,35 & 4,26 & 7,30 & 4,89 & 7,05 \\
\hline 140 & 23,47 & 33,72 & 4,15 & 7,45 & 5,02 & 7,26 \\
\hline 210 & 25,15 & 35,97 & 4,50 & 7,30 & 5,10 & 7,28 \\
\hline 280 & 23,70 & 36,06 & 4,40 & 7,92 & 5,16 & 7,97 \\
\hline Valor F & $1,681^{\mathrm{ns}}$ & $0,535^{\text {ns }}$ & $0,517^{\text {ns }}$ & $0,786^{\text {ns }}$ & $1,268^{\mathrm{ns}}$ & $2,684^{\text {ns }}$ \\
\hline Regressão & --- & --- & --- & --- & --- & --- \\
\hline Interação & --- & --- & --- & --- & --- & --- \\
\hline CV (\%) & 12,70 & 11,44 & 13,68 & 11,74 & 17,84 & 10,03 \\
\hline
\end{tabular}

*Médias seguidas de mesma letra maiúscula na coluna, para cada fator estudado, não diferem entre si pelo teste de Tukey a $5 \%$ de probabilidade. ${ }^{\text {ns }}$ não significativo; * significativo a $5 \%$ de probabilidade. 
Tabela 6. Valores médios de massa fresca de parte aérea (MFPA) massa seca de parte aérea (MSPA), massa fresca de raiz (MFR) massa seca de raiz (MSR) e produtividade comercial (PC), produtividade não comercial (PNC) e produtividade total (PT) de rabanete em função da adubação fosfatada. Ipameri-GO, 2015.

\begin{tabular}{|c|c|c|c|c|c|c|c|}
\hline \multirow{2}{*}{ Fontes } & MFPA & MSPA & MFR & MSR & $\mathrm{PC}$ & $\mathrm{PNC}$ & PT \\
\hline & \multicolumn{4}{|c|}{------------- g ------------- } & \multicolumn{3}{|c|}{-------- t ha ${ }^{-1}--------$} \\
\hline Superfosfato Simples & $30,36 \mathrm{a}$ & $6,40 \mathrm{~b}$ & $65,09 \mathrm{a}$ & $7,73 \mathrm{a}$ & $29,52 \mathrm{a}$ & $13,27 \mathrm{a}$ & $42,77 \mathrm{a}$ \\
\hline Superfosfato Triplo & $31,32 \mathrm{a}$ & $6,91 \mathrm{a}$ & $64,28 \mathrm{a}$ & $7,91 \mathrm{a}$ & 30,18 a & $15,77 \mathrm{a}$ & $45,90 \mathrm{a}$ \\
\hline Valor F & $0,982^{\text {ns }}$ & $5,497 *$ & $0,032^{\mathrm{ns}}$ & $0,225^{\mathrm{ns}}$ & $0,027^{\mathrm{ns}}$ & $2,103^{\text {ns }}$ & $0,008^{\mathrm{ns}}$ \\
\hline \multicolumn{8}{|l|}{ Doses $\left(\mathrm{kg} \mathrm{ha}^{-1}\right)$} \\
\hline 0 & 39,40 & 6,86 & 67,07 & 7,96 & 20,60 & 14,14 & 34,70 \\
\hline 70 & 40,50 & 7,16 & 56,12 & 7,58 & 29,36 & 14,33 & 43,79 \\
\hline 140 & 41,28 & 6,03 & 62,02 & 7,36 & 35,53 & 14,52 & 50,12 \\
\hline 210 & 39,32 & 6,35 & 65,21 & 7,77 & 35,98 & 14,71 & 50,80 \\
\hline 280 & 39,60 & 6,50 & 73,01 & 8,41 & 27,78 & 14,90 & 42,61 \\
\hline Valor F & $1,597^{\mathrm{ns}}$ & $2,549^{\text {ns }}$ & $1,527^{\mathrm{ns}}$ & $0,887^{\mathrm{ns}}$ & $1,991^{\mathrm{ns}}$ & $0,550^{\mathrm{ns}}$ & $0,917^{\mathrm{ns}}$ \\
\hline Regressão & --- & --- & --- & --- & --- & --- & --- \\
\hline Interação & --- & --- & --- & --- & --- & --- & --- \\
\hline$\overline{\mathrm{CV}(\%)}$ & 35,48 & 10,23 & 22,07 & 15,31 & 42,44 & 37,46 & 32,26 \\
\hline
\end{tabular}

*Médias seguidas de mesma letra maiúscula na coluna, para cada fator estudado, não diferem entre si pelo teste de Tukey a 5\% de probabilidade. ${ }^{\text {ns }}$ não significativo; * significativo a $5 \%$ de probabilidade.

\section{Conclusões}

A aplicação de fontes e doses de fósforo não influenciaram nos atributos morfológicos e na produtividade da cultura da cenoura e rabanete.

Para a cultura da beterraba as fontes de fósforo não influenciaram em nenhuma variável e as doses de fósforo incrementaram os atributos morfológicos e a produtividade.

\section{Agradecimentos}

À Universidade Estadual de Goiás (UEG), Campus Ipameri, pelo suporte na condução do projeto e pela bolsa produtividade PROBIP ao quarto autor. Ao Conselho Nacional de Desenvolvimento Científico e Tecnológico (CNPq) pela bolsa de iniciação cientifica.

\section{Referências Bibliográficas}

ALVES, A. U.; PRADO, R. M.; GONDIM, A. R. O.; FONSECA, I. M.; CECÍLIO FILHO, A. B. Desenvolvimento e estado nutricional da beterraba em função da omissão de nutrientes. Horticultura Brasileira, Brasília-DF, v. 26, n. 2, p. 292-295, 2008.

ARAÚJO, C.; ZÁRATE, N. A. H.; VIEIRA, M. C. Produção e perda de massa pós-colheita de cenoura 'Brasília', considerando doses de fósforo e de cama de frango semi decomposta. Acta Scientiarum. Agronomy, Maringá-PR, v. 26, n. 2, p. 131-138, 2004.
AVALHAES, C. C.; PRADO, R. M.; GONDIM, A. R. O.; ALVES, A. U.; CORREIA, M. A. R. Rendimento e crescimento da beterraba em função da adubação com fósforo. Scientia Agraria, Curitiba-PR, v. 10, n. 1, p. 75-80, 2009.

BISSANI, C. A.; GIANELlO, C.; CAMARGO, F. A. O.; TEDESCO, M. J. Fertilidade dos solos e manejo da adubação de culturas. Porto Alegre-RS: Editora Metrópole, 2008. 344 p.

CARDOSO, M. R. D.; MARCUZZO, F. F. N.; BARROS, J. R. Classificação climática de Köppen-Geiger para o Estado de Goiás e o Distrito Federal. ACTA Geográfica, Roraima-RR, v. 8 , n. 16 , p. $40-55,2014$.

FILGUEIRA, F. A. R. Novo Manual de Olericultura: Agrotecnologia moderna na produção e comercialização de hortaliças. 3. ed. Viçosa-MG: UFV, 2012. 421 p.

GRANT, C. A.; PLATEN, D. N.; TOMAZIEWICZ, D. J.; SHEPPARD, S. C. A importância do fósforo no desenvolvimento inicial da planta. Informações Agronômicas, Piracicaba-SP, n. 95, set., p. 1-5, 2001.

HARGER, N.; BRITO, O. R.; RALISCH, R.; ORTIZ, F. R.; WATANABE, T. S. Avaliação de fontes e doses de fósforo no crescimento inicial do milho. Semina: Ciências Agrárias, Londrina-PR, v. 28, n. 1, p. 39-44, 2007.

HAVLIN, J. L.; BEATON, J. D.; TISDALE, S. L.; NELSON, W. L. Soil fertility and fertilizers: An introduction to nutrient management. 7. ed. New Jersey: Pearson Prentice Hall, 2005. $515 \mathrm{p}$. 
KOETZ, M.; CARVALHO, K. S.; BOMFIM-SILVA, E. M.; REZENDE, C. G.; SILVA, J. C. Rúcula submetida a doses de fósforo em Latossolo Vermelho do cerrado. Enciclopédia Biosfera, Goiânia-GO, v. 8, n. 15, p. 1554-1562, 2012.

LUZ, J. M. Q.; QUEIROZ, A. A.; BORGES, M.; OLIVEIRA, R. C.; LEITE, S. S.; CARDOSO, R. R. Influence of phosphate fertilization on phosphorus levels in foliage and tuber yield of the potato cv. Ágata. Semina: Ciências Agrárias, LondrinaPR, v. 34, n. 2, p. 649-656, 2013.

MARSCHNER, H. Mineral nutrition of higher plants. 2 ed. London: Academic Press, 1995. 889 p.

NAVES FILHO, A. R.; PEREIRA, E. D.; NAVES, M. R.; YURI, J. E. Efeito do uso de diferentes doses de fósforo na cultua da cenoura. Embrapa: Brasília. 2004. 4 p. Disponível em:

<http://www.abhorticultura.com.br/biblioteca/arquivos/Downl oad/Biblioteca/45_0107.pdf> Acesso em: 10 fev. 2014.

NUNES, J. A. S.; BOMFIM-SILVA, E. M.; MOREIRA, J. C. F. Produção de rabanete submetido à adubação fosfatada. Cerrado Agrociências, Patos de Minas-MG,v. 2, n. 5, nov. p. 33-44, 2014.

OLIVEIRA, F. R. A.; OLIVEIRA, F. A. MEDEIROS, J. F.; SOUSA, V. F. L.; FREIRE, A. G. Interação entre salinidade e fósforo na cultura do rabanete. Revista Ciência Agronômica, Fortaleza-CE, v. 41, n. 4, p. 519-526, 2010.

OLIVEIRA, R. J. P.; GATIBONI, L. C.; VALICHESKI, R. R.; MIQUELLUTI, D. J.; BRUNETTO, G. Calibração da adubação fosfatada e potássica para beterraba na região do
Vale do Itajaí. Horticultura Brasileira, Brasilia-DF, v. 34, n. 2, p. 210-215, 2016.

RAIJ, B. V. Fertilidade do solo e adubação. São Paulo-SP: Agronômica Ceres, 1991. 343 p.

RAIJ, B. V.; CANTARELlA, H.; QUAGGIO, J. A.; FURLANI, A. M. C. (Ed.). Recomendações de adubação e calagem para o Estado de São Paulo. 2. ed. Campinas-SP: Instituto Agronômico/Fundação IAC, 1997. 285 p. (Boletim Técnico, 100).

RAIJ, B. V.; CANTARELLA, H.; QUAGGIO, J. A.; FURLANI, A. M. C. Recomendações de adubação e calagem para o Estado de São Paulo. 2.ed. Campinas-SP: IAC, 1996. 285 p. (Boletim Técnico, 100).

RIBEIRO, A. C.; GUIMARÃES, P. T. G.; ALVAREZ, V. H. Recomendações para o uso de corretivos e fertilizantes em Minas Gerais - 5a aproximação. Viçosa-MG: UFV, 1999. 359 p.

SANTOS, H. G.; JACOMINE, P. K. T.; ANJOS L. H. C.; OLIVEIRA, V. A.; LUMBRERAS, J. F.; COELHO, M. R.; ALMEIDA, J. A.; CUNHA T. J. F.; OLIVEIRA, J. B. Sistema brasileiro de classificação de solos. 3. Brasília-DF: Embrapa, 2013. 353 p.

SILVA, L. M.; BASÍLIO, S. A.; SILVA JÚNIOR, R. L.; BENETT, K. S. S.; BENETT, C. G. S. Aplicação de nitrogênio, potássio e cálcio na cultura da cenoura. Revista de Agricultura Neotropical, Cassilândia-MS, v. 4, n. 3, p. 6976, 2017. 